\title{
SUITABILITY INDEX ASSESSMENT FOR COLLECTION BIN ALLOCATION USING ANALYTICAL HIERARCHY PROCESS (AHP) CASCADED TO ARTIFICIAL NEURAL NETWORK (ANN)
}

\author{
Debasree Purkayastha ${ }^{1, *}$, Mrinmoy Majumder ${ }^{2}$ and Sumanta Chakrabarti ${ }^{3}$ \\ ${ }^{1}$ Department of Civil Engineering, Indian Institute of Technology Roorkee, Roorkee Uttarakhand 247667, India \\ ${ }^{2}$ Department of Civil Engineering, National Institute of Technology, Agartala, P.O.: Former Tripura Engineering College, Barjala, Jirania \\ 799046 Tripura (W), India \\ ${ }^{3}$ Maharaja Bir Bikram University, Agartala, P.O.: Agartala College, Tripura (W) 799004, India
}

Article Info:

Received:

26 July 2018

Revised:

13 September 2019

Accepted:

28 October 2019

Available online:

20 November 2019

Keywords:

Municipal Solid Waste (MSW)

Bin allocation

Suitability Index (S.I)

Analytical Hierarchy Process (AHP)

Artificial Neural Network (ANN)

\begin{abstract}
Municipal solid waste is an inevitable outcome of anthropogenic activities. Proper sustainable solid waste management is the need of the hour. In this study, a Suitability Index (S.I) has been determined which can measure the relative importance of a district with regard to its necessity or requirement of collection bins in comparison to other districts in a municipality. The S.I was computed using Analytical Hierarchy Process cascaded to Artificial Neural Network. Four criteria viz. Demographic, Social, Economic and Technical considerations and seven factors viz. Population Density (P.D), Street Width (S.W), Waste Generation Rate (W.G.R), Income Group Distribution (I.G.D), Average Minimum Distance between the bins (MIN.D), Available Number of Bins (A.N.B) and Cost of Waste Bins (C.W.B) were considered for developing the model. Available Number of Bins was found to have the highest impact on the model followed by C.W.B, W.G.R, MIN D., I.G.D, P.D, and S.W. This index will particularly help developing countries with resource constraint and unskilled labor force in Solid Waste Management. It will help such countries to easily locate districts in urgent need of collection bins with an easily available set of data and will help in increasing collection efficiency.
\end{abstract}

\section{INTRODUCTION}

Creation of Solid Waste is an inevitable part of human activities, especially in the urban crowd. Municipal Solid Waste Management is one of the most pressing problems faced by most of the cities around the globe especially the developing countries. In India, the municipal agencies spend $5-25 \%$ of their budget on Solid Waste Management (SWM). But unfortunately, high capital investment in the SWM sector is not necessarily leading to improvements in the quality of service (National Solid Waste Association of India (NSWAI), 2008). Almost $85 \%$ of the total expenditure in SWM is spent on collection (Ghose, Dikshit, \& Sharma, 2006). Similar reports of huge cost investment in the collection of solid waste have been made by other researchers (Ghiani, Laganà, Manni, \& Triki, 2012; Ghiani, Manni, Manni, \& Toraldo, 2014; González-Torre, Adenso-Díaz, \& Ruiz-Torres, 2003; Kao \& Lin, 2002) and municipalities as well.

Location-allocation modeling is the method of optimizing the location of centers or facilities and allocating consumers or demands to those centers (Valeo, Baetz, \& Tsan- is, 2002). In spite of being one of the significant factors in the successful achievement of SWM, location-allocation problem of sitting storage depots have achieved very less importance around the globe. When determining the type and size of these bins during system planning and design, the solid waste estimation and allocation are not adequately addressed. The vast majority of the studies mainly investigated the vehicular transportation of waste from bins to the disposal sites. Although these processes require heavy vehicles and machinery, the efficiency of these depends upon the number, location, type and size of bins as well as the frequency of waste removal required (Vijay, Gupta, Kalamdhad, \& Devotta, 2005). Parrot et al. (Parrot, Sotamenou, \& Dia, 2009) noted that the spatial distribution of the garbage accumulation points (GAPs) inside towns often does not take the needs of all local residents into account in terms of quantities of waste produced and distance from their dwelling. They also found that when the average distance to the closest GB is long, there is generally a low percentage (37.4) of people who dump their waste in them. The long-distance explains why households dispose 
of domestic waste in open areas. Similar concerns about the non-convenient location of the GAPs are expressed by Zia \& Devadas (Zia \& Devadas, 2008).

Various location-allocation modeling has been widely used for facility location planning in both the public and private sectors (Beaumont, 1987). Three different approaches have been attempted by researchers for addressing the location-allocation modeling viz. Geographical Information System (GIS) (El-Hallaq \& Mosabeh, 2019; Erfani, Danesh, Karrabi, \& Shad, 2017; Kao \& Lin, 2002; Khan \& Samadder, 2016; Nithya, Velumani, \& Senthil Kumar, 2012; Vijay et al., 2005; Vu, Ng, \& Bolingbroke, 2018), integer programming (Coutinho-Rodrigues, Tralhão, \& Alçada-Almeida, 2012; Ghiani et al., 2012, 2014; Rathore, Sarmah, \& Singh, 2019) and algorithm (Di Felice, 2014; Hemmelmayr, Doerner, Hartl, \& Vigo, 2013). Some of them have tried to club GIS with the other two to suggest best possible locations of bin allocation (Arribas, Blazquez, \& Lamas, 2010; Erfani, Danesh, Karrabi, Shad, \& Nemati, 2018; Karadimas \& Loumos, 2008; Tralhão, Coutinho-Rodrigues, \& Alçada-Almeida, 2010). A detailed literature study of the Location-allocation modeling in SWM has been conducted by Purkayastha et al. (Purkayastha, Majumder, \& Chakrabarti, 2015). The use of multi-criteria decision making (MCDM) approaches for location-allocation solutions in solid waste (Mondal, Speier, \& Weichgrebe, 2019) has been extremely limited. Moreover, there has been no study on the location-allocation of collection bin using Analytical Hierarchy Process (AHP) cascaded to Artificial Neural Network (ANN).

In the present study, an index known as the Suitability Index (S.I.) has been developed with the application of AHP and ANN to address the location-allocation problem in SWM. The developed index can identify the area or district which is in urgent need of collection bins. This index will be most beneficial for SWM of developing countries who have resource constraints and are operating majorly with unskilled manpower. This index can also prioritize the area or district on the basis of its urgency in terms of collection bin requirement. Therefore SI can aid in providing collection bins to areas with immediate requirements under limited resource constraint conditions.

\section{METHODS USED}

The main objective of this model is to develop a Suitability Index (S.I.) for location-allocation of the collection bin. The S.I. is a comparative scale which can measure the relative importance of an area or district (hereafter known as a ward) with regard to its necessity or requirement of collection bins in comparison to other wards in a municipality. The study utilized two methods to develop this S.I: Multi-criteria decision making (MCDM) and Artificial Neural Network (ANN).

\subsection{Multi-criteria decision making (MCDM)}

MCDM methods have found a wide application in decision-making objectives over a wide decade of time. MCDM method is applied to compute the priority or weight of importance of the factors correlated to the objective of the study. There are various type MCDM techniques like Weighted Sum Method (WSM), Weighted Product Method (WPM), Simple Additive Weighting (SAW), and Analytical Hierarchy Process (AHP). In the present study, the AHP method has been used as because in this study relative importance as well as both qualitative and quantitative parameters have been considered. The other MCDM technique such as WSM and SAW doesn't incorporate pair wise comparison or relative weights of importance of criterias and alternatives whereas AHP incorporates it. Moreover they only consider quantitave variables, whereas AHP can include both qualitative and quantitative variables (Ghosh, Chakraborty, Saha, Majumder, \& Pal, 2016).

\subsection{Artificial Neural Network (ANN)}

ANN is a computational model composed of many elements (known as neurons) connected by a variable weight. It was Warren McCulloch, a neurophysiologist, and Walter Pitts, a young mathematician, who in 1943 proposed the first ANN model known as McCulloch-Pitts (MP) Model. In the MP model, the activation ( $\mathrm{x}$ ) is given by a weighted sum of its $M$ input values $\left(a_{i}\right)$ and a bias term $(\theta)$. The output signal (s) is typically a nonlinear function $f(x)$ of the activation value $x$. the objective function of the MP model or basic ANN model is given by:

$s=f\left(\sum_{i=1}^{M} w_{i} a_{i}-\theta\right)$

\section{METHODOLOGY}

The objective of the present study is to establish a Suitability Index which will help in determining the priority of locating waste collection bin in a geographical area. Suitability Index (S.I) is the ratio of beneficiary factors to nonbeneficiary factors. Suitability Index can be mathematically represented according to equation (2).

$$
S . I=\frac{\sum(W X \text { Beneficiary factors })}{\sum(W X \text { Non-Beneficiary factors })}
$$

$\mathrm{W}=$ Weightage of the importance factor. This weight of importance is determined by MCDM techniques.

The "Beneficiary factors" are those which increase the probability of a place being suitable for collection bin allocation i.e. with the increase in the value of these factors the S.I value also increases thus increasing the suitability of a place for collection bin allocation. For e.g. population density, waste generation rate, etc.

The "Non-Beneficiary factors" are those which decrease the probability of a place being suitable for collection bin allocation i.e. with the increase in the value of these factors the S.I value decreases thus decreasing the suitability of a place for the collection bin allocation and vice versa. For e.g. cost of the bin, the number of bins already available in an area, etc.

\subsection{Weightage Computation of factors using AHP technique}

The AHP method requires three steps: (1) Selection of criteria (2) Selection of alternatives (3) Application of aggregation method (Ghosh et al., 2016). 


\subsubsection{Selection of criteria}

For the present study, the weightage of all the beneficiary and non-beneficiary parameters needs to be determined. Henceforth all the beneficiary and non-beneficiary parameters were considered as alternatives. In this study, the weight of importance of the alternatives was established with respect to some criteria established from the expert survey and literature survey. In order to derive this index, a critical literature survey was conducted to find out the factors and criteria which were most significant to the placement of collection bins. The questionnaire adopted for the expert survey was prepared using Google form and is provided in supplementary materials (Annex-A). The expert survey was conducted through face to face interview and Social networking Media (Researchgate, Gmail, LinkedIn, and Facebook). Four criteria which were selected from the extensive literature study were found to be significant according to the expert study as well and are: Demographic Considerations (D1), Social Considerations (S1), Economic Considerations (E1) and Technical Considerations (T1). Four of these criteria are very inclusive in nature on a broader aspect and include all factors affecting bin allocation. According to both literature and expert study four of these criteria were suggested and no other criteria was suggested. Since all these criteria received significant importance according to both expert and literature study, four of them were considered in bin allocation problem in this study.

\subsubsection{Selection of alternatives}

The alternatives which were found to be most important in deciding locations for collection bin allocations based on expert and literature surveys were: Population Density (P.D), Street Width (S.W), Waste Generation Rate (W.G.R), Income Group Distribution (I.G.D), Cost of Waste Bin (C.W.B), Available Number of Bins (A.N.B) and Minimum Distance between Bins (MIN. D) (Table 1). These alternatives were further divided into beneficiary and nonbeneficiary parameters. In this model Population Density (P.D), Street Width (S.W), Waste Generation Rate (W.G.R), Income Group Distribution (I.G.D) and Minimum Distance between Bins (MIN. D) were considered as beneficiary factors i.e. with increase in value of each of these factors the S.I value increased and vice versa. In this model Cost of Waste Bin (C.W.B) and Available Number of Bins (A.N.B) were considered as non-beneficiary factors i.e. with the increase in the value of each of these factors the S.I value decreased.

\subsubsection{Application of aggregation method}

Both the expert survey and literature survey was carried out further to estimate the importance of criteria and alternatives over each other. An expert survey was conducted on a set of a questionnaire asking to rank the alternatives with respect to each criterion on a scale of 1 to 9,1 being very weak and 9 being extremely strong. The ranking was provided in the manner that the alternative under criteria which obtained the highest score was ranked 1 , the alternative with the second-highest score was ranked 2 and so on. The rank of the criteria and alternative were established based on the literature survey and expert survey. In case if two or more alternatives under the same criteria obtained the same rating then in such cases all those alternatives were given the same rating and the in-between ranks were skipped The same methodology was adopted for other criteria too.

A $4 \times 4$ matrix was developed to find out the weightage of criteria.

$c=\{n X n\}$

Where, $\{\mathrm{n}\}=\{\mathrm{D} 1, \mathrm{~S} 1, \mathrm{E} 1, \mathrm{~T} 1\} \in \mathrm{R}$, where $\mathrm{R}$ is the set of real numbers.

Similarly, the alternatives are compared with each other based on their importance over each other according to each of the criteria ' $n$ ':

$A=\left\{f_{i} X f_{i}\right\}$

Where, $\left\{\mathrm{f}_{\mathrm{i}}\right\}=\{\mathrm{PD}, \mathrm{SW}, \mathrm{WGR}, \mathrm{IGD}, \mathrm{MIND}, \mathrm{CWB}, \mathrm{ANB}\} \in \mathrm{R}$, where $\mathrm{R}$ is the set of real numbers.

The hierarchy of decision making is shown in Figure 1.

In the case of AHP generally, the Saaty scale is used which was proposed by Saaty in the year of 1980 [10]. The scale utilized either even or odd number to represent the importance of the criteria and alternatives with respect to each other in the Pairwise Comparison Matrix (PCM). For intermediate importance, the rating in between the evens or odds is utilized. But still, there is a lot of confusion regarding what can be used for the representation of a high difference of importance and minor difference of importance between two alternative or criteria.

That is why, in the present study, we use the rank of the criteria and alternatives based on their magnitude or qualitative ratings and then ration of rank of the criteria/alternative compared and the rank of the other criteria/alternative with which it is being compared was found out (the rank is assigned in such a way that the relationship of the criteria with the decision objective can be reflected). The ratio is then reversed to give the exact difference of importance coherent to decision objective.

The direct use of rank to estimate the importance will ensure uniformity and remove the confusion involving the rating that can be given to depict two different levels of importance that exist between two different criteria or alternative.

\subsection{Formulation of Suitability Index (S.I.)}

The final S.I formula was formulated as:

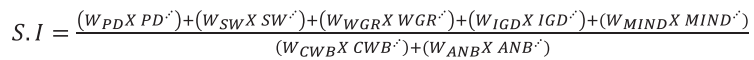

Where,
PD $:=$ Normalised value of PD WGR $:=$ Normalised value of WGR

MIND $:=$ Normalised value of MIND

ANB $:=$ Normalised value of ANB

SW $:=$ Normalised value of SW

IGD $:=$ Normalised value of IGD

CWB $\cdot=$ Normalised value of CWB
$\mathrm{W}_{\mathrm{SW}}=$ Weightage of SW

$\mathrm{W}_{\mathrm{IGD}}=$ Weightage of IGD

$\mathrm{W}_{\mathrm{CWB}}=$ Weightage of $\mathrm{CWB}$

$\mathrm{W}_{\mathrm{PD}}=$ Weightage of $\mathrm{PD}$

$\mathrm{W}_{\mathrm{WGR}}=$ Weightage of WGR

$\mathrm{W}_{\text {MIND }}=$ Weightage of MIND

$\mathrm{W}_{\mathrm{ANB}}=$ Weightage of ANB 
TABLE 1: Table showing detail description of the Criteria and sub-criteria used in the AHP method for the present study.

\begin{tabular}{|c|c|c|c|c|}
\hline Criteria & Alternatives & Description & Mathematical formulations & Literature reference \\
\hline $\begin{array}{l}\text { Demographic considerations: } \\
\text { The demography of an } \\
\text { area is very important } \\
\text { while designing any waste } \\
\text { management technology for } \\
\text { an area. Suggested Waste } \\
\text { management technology } \\
\text { varies from place to place } \\
\text { depending on the demogra- } \\
\text { phy of that place. }\end{array}$ & $\begin{array}{l}\text { Population density } \\
\text { (P.D) }\end{array}$ & $\begin{array}{l}\text { Population density is an } \\
\text { important parameter in } \\
\text { deciding the requirement } \\
\text { of total number of bins in } \\
\text { an area. }\end{array}$ & P.D $\left(\right.$ per $\left.\mathrm{km}^{2}\right)=\frac{\text { Population }}{\text { Area }}$ & $\begin{array}{l}{[3,4,6,8,12,17,19} \\
21,22,28-34]\end{array}$ \\
\hline $\begin{array}{l}\text { Social considerations: } \\
\text { Suggested Waste manage- } \\
\text { ment technology will depend } \\
\text { upon the social situation } \\
\text { of the locality. For e.g. the } \\
\text { waste characteristic will be } \\
\text { different depending upon the } \\
\text { income level of most of the } \\
\text { people living in the society. }\end{array}$ & Street Width (S.W) & $\begin{array}{l}\text { Width of the street where } \\
\text { the collection bin needs to } \\
\text { be provided decides which } \\
\text { size of bin can be provided } \\
\text { in an area as because each } \\
\text { size of bin are collected by a } \\
\text { particular collection vehicle } \\
\text { which needs a particular } \\
\text { width of street for collecting } \\
\text { wastes from that bin. }\end{array}$ & - & $\begin{array}{l}{[8,12,17,19,21} \\
28-31]\end{array}$ \\
\hline $\begin{array}{l}\text { Economic considerations: } \\
\text { The municipal budget is } \\
\text { always a constrain in Solid } \\
\text { waste management. Hence } \\
\text { to take care of the economic } \\
\text { viability we need to consider } \\
\text { economic optimization and } \\
\text { feasibility before deciding the } \\
\text { waste management option. }\end{array}$ & $\begin{array}{l}\text { Waste Generation } \\
\text { Rate (W.G.R) }\end{array}$ & $\begin{array}{l}\text { Waste Generation Rate } \\
\text { decides the total quantity } \\
\text { of bins needed to provide } \\
\text { collection bin facilities for } \\
\text { all the wastes generated in } \\
\text { a locality. }\end{array}$ & $\begin{array}{l}\text { W.G.R }\left(\mathrm{m}^{3}\right)=[p c w g X P \times \rho]-A . N . B \\
\text { Pcwg = Per capita waste generation }\left(\frac{\mathrm{kg}}{\text { person }} \text { day }\right. \\
P=\text { Total population of the ward } \\
\rho=\text { Density of waste }\left(\frac{\mathrm{kg}}{\mathrm{m}^{3}}\right) \\
\text { A.N.B = Available Number of Bin }\end{array}$ & $\begin{array}{l}{[3,4,6,12,17,19,} \\
21,22,28,29,31,32]\end{array}$ \\
\hline \multirow[t]{4}{*}{$\begin{array}{l}\text { Technical Considerations: } \\
\text { It includes the present status } \\
\text { of infrastructure available } \\
\text { and provided by the munic- } \\
\text { ipality. }\end{array}$} & $\begin{array}{l}\text { Income Group Dis- } \\
\text { tribution (I.G.D) }\end{array}$ & $\begin{array}{l}\text { Income level of a section of } \\
\text { society decides the amount } \\
\text { and kind of waste generated } \\
\text { and the collection bin facil- } \\
\text { ities needed to account all } \\
\text { the waste. }\end{array}$ & $\begin{array}{l}\text { High Income Group (Rating-3) } \\
\text { Medium Income Group (Rating-2) } \\
\text { Low Income Group (Rating-1) }\end{array}$ & {$[8,30]$} \\
\hline & $\begin{array}{l}\text { Cost of Waste Bin } \\
\text { (C.W.B) }\end{array}$ & $\begin{array}{l}\text { In general their needs to be } \\
\text { a compromise between eco- } \\
\text { nomic viability and resource } \\
\text { requirement. The number of } \\
\text { extra bins needed in an area } \\
\text { in addition to the already } \\
\text { provided bins amount to a } \\
\text { cost and Cost of Waste Bin } \\
\text { (C.W.B) depicts that value. }\end{array}$ & $\begin{array}{l}C . W . B=M-\sum_{i=1}^{n} N_{i} X C_{i} \\
M=\text { Maximum cost of bins if a ward is pro- } \\
\text { vided with actual required number of bins of } \\
\text { any one type in " } n \text { " Number of types so that } \\
\text { the total volume of waste produced in that } \\
\text { ward is collected in bins and no waste is } \\
\text { left unattended or uncollected. } \\
n=\text { Number of types of bins in an munici- } \\
\text { pality } \\
N_{i}=\text { Available Number of Bins of type i } \\
\text { (where } \mathrm{i}=1,2,3, \ldots \ldots \ldots ., \mathrm{n}) \\
C_{i} \text { (Currency unit as per the country) = Cost } \\
\text { of Each Bin of type } \mathrm{i}\end{array}$ & {$[17]$} \\
\hline & $\begin{array}{l}\text { Available Number } \\
\text { of Bin (A.N.B) }\end{array}$ & $\begin{array}{l}\text { Available Number of Bin } \\
\text { (A.N.B) is the quantity of } \\
\text { bins already provided to an } \\
\text { area. This factor decides } \\
\text { whether any further bins } \\
\text { should be provided in a area } \\
\text { in addition to the already } \\
\text { provided bins to address re- } \\
\text { source constraint situation. }\end{array}$ & $\begin{array}{l}\text { A.N.B }\left(\mathrm{m}^{3}\right)=\sum_{i=1}^{n} N_{i} X V_{i} \\
N_{i}=\text { Available Number of Bins of type } \mathrm{i} \\
(\text { where } \mathrm{i}=1,2,3, \ldots \ldots \ldots, \mathrm{n}) \\
V_{i}\left(\mathrm{~m}^{3}\right)=\text { Volume of Bin of type } \mathrm{i} \text { (where } \\
\mathrm{i}=1,2,3, \ldots \ldots \ldots, \mathrm{n})\end{array}$ & {$[3,4,17]$} \\
\hline & $\begin{array}{l}\text { Minimum Distance } \\
\text { between Bins } \\
\text { (MIN. D) }\end{array}$ & $\begin{array}{l}\text { Minimum Distance between } \\
\text { Bins denotes the average } \\
\text { minimum distance between } \\
\text { the bins an area. This factor } \\
\text { represents the frequency of } \\
\text { bin placement in an area, so } \\
\text { that places in an area with } \\
\text { low bin frequencies can be } \\
\text { identified. }\end{array}$ & $\begin{array}{l}\text { MIN.D (meter) }=\frac{d_{\min }+d_{\max }}{2} \\
d_{\min }=\text { Minimum distance between bins in } \\
\text { a ward } \\
d_{\max }=\text { Maximum distance between bins in } \\
\text { a ward }\end{array}$ & $\begin{array}{l}{[3,4,6,8,19,22} \\
33,34]\end{array}$ \\
\hline
\end{tabular}

\subsection{ANN Model Formulation for Suitability Index (S.I.)}

To predict S.I. Artificial Neural Network (ANN) was used. GMDH Shell software was used for carrying out the
ANN-based prediction. GMDH stands for "Group Method of Data Handling". The main idea of GMDH is to build an analytical function in a feedforward network based on a quadratic node transfer function whose coefficients are 
obtained using a regression technique (Farlow, 1981). It was first proposed in 1966 by a Russian cyberneticist, A.G. Ivakhnenko.

The inputs of the model were the random normalised values of Population Density (P.D), Street Width (S.W), Waste Generation Rate (W.G.R), Income Group Distribution (I.G.D), Cost of Waste Bin (C.W.B), Available Number of Bins (A.N.B) and Minimum Distance between Bins (MIN. D). The input function of the ANN model is shown in Eqn. 4. The output was the Suitability Index (S.I). The model predicted the S.I value for 1000 data. Then a case study was conducted on Agartala Municipality to predict its S.I for the entire municipality, which has been presented in Section 4.3.

\subsection{Description of the case study area}

Agartala the capital city of Tripura is one of the eight North-Eastern states of India. It is situated along $23^{\circ} 45^{\prime}$ - $23^{\circ} 55^{\prime} \mathrm{N}$ latitude and $91^{\circ} 15^{\prime}-91^{\circ} 20^{\prime} \mathrm{E}$ longitude, in the flood plains of the Haora River. The city has been an important border-trading town with trading linkages with Bangladesh. The National Highway (NH)-44 connects Agartala with Assam. The climate of Agartala is tropical monsoon type. The average rainfall of the city is about $220 \mathrm{~cm}$.

The solid waste management of Agartala city is carried out by Agartala Municipal Corporation (AMC) established in 1871. Agartala Municipal area is divided into 4 zones and 35 wards. The overall population of Agartala Municipal area is 4, 70,190 with an overall area of 61.718 sq. km. A map of the Agartala Municipal Corporation (AMC) is shown in Figure 2.

The wastes generated in Agartala are of two types- Municipal solid Waste and Biomedical Waste. In our study we are considering only Municipal Solid Waste (MSW). The major waste generating sources of MSW are household

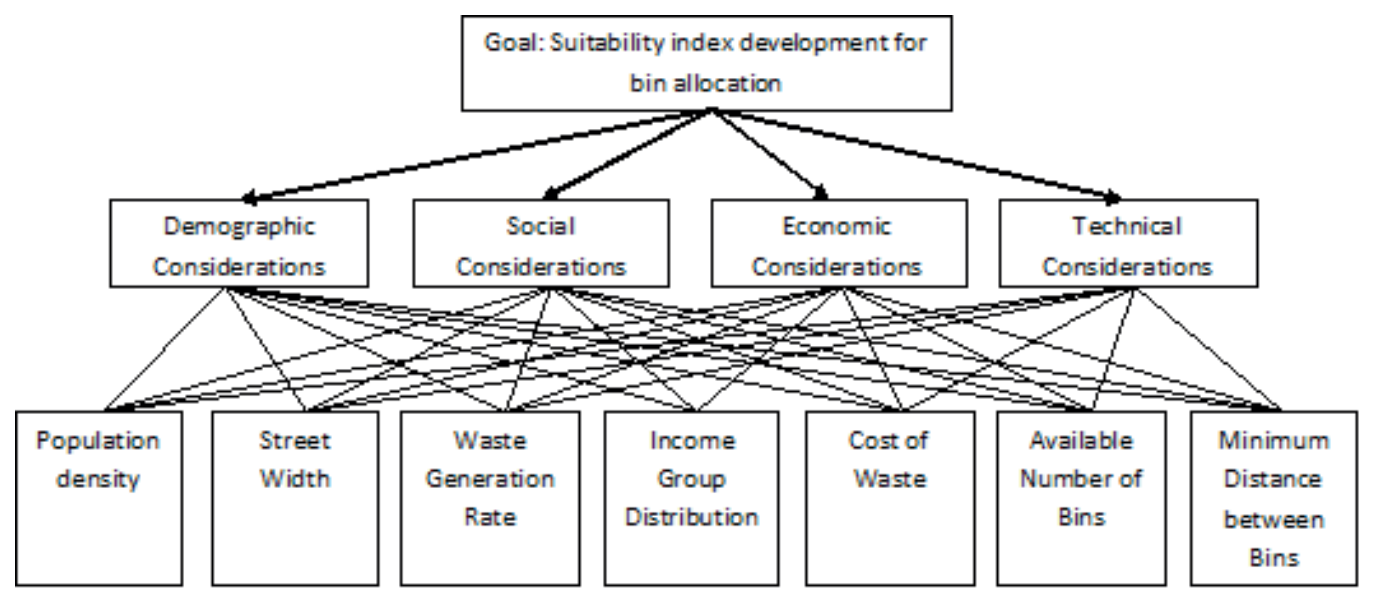

FIGURE 1: Hierarchy Structure of the AHP Modely.

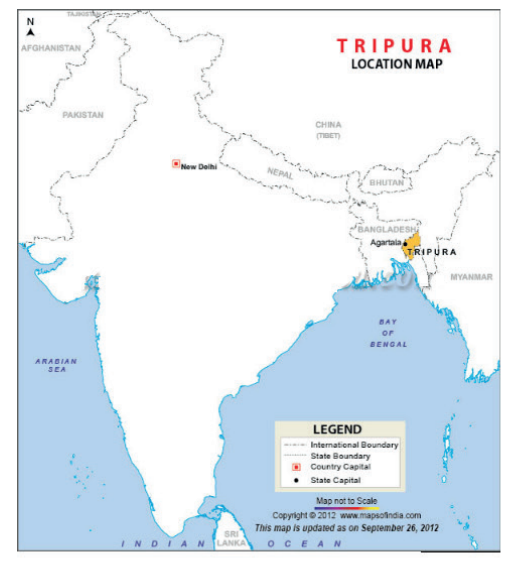

MAP OF INDIA

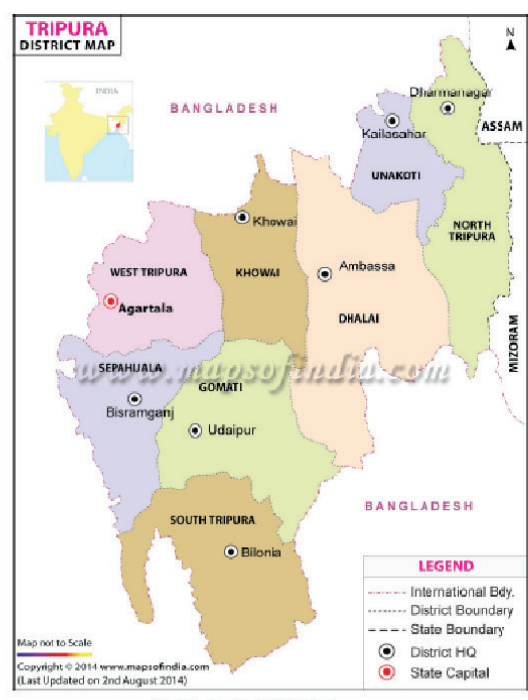

MAP OF TRIPURA

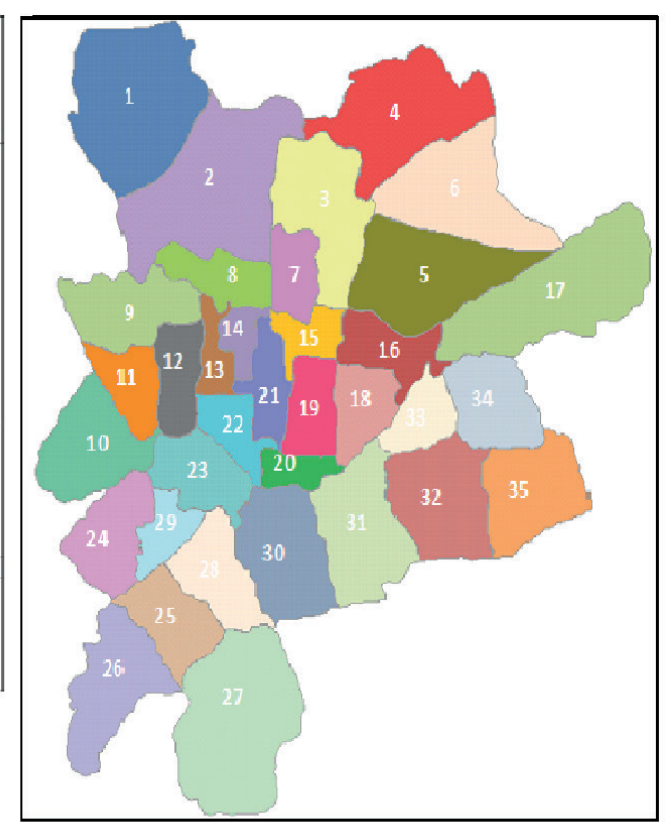

WARDWISE MAP OF AGARTALA MUNICIPALITY

FIGURE 2: Map of the study area. 
wastes, institutional wastes, market (vegetable and fish) wastes, street litters and drain silts.

Agartala Municipal Corporation (AMC) has placed more than 447 number of medium $\left(1.1 \mathrm{~m}^{3}\right)$ (Figure $3 a$ ) and 55 large sizes $\left(4.5 \mathrm{~m}^{3}\right.$ ) (Figure $3 \mathrm{~b}$ ) bins/containers by the side of major roads and in market and commercial areas.

The data table for formulating the model for AMC area is shown below in Table 2. The data of Population density (P.D), Available number of Bins (A.N.B) and Cost of Waste Bins (C.W.B) has been provided by AMC. The data on Income Group Distribution (I.G.D) isn't available with AMC, so all the wards have been assumed to fall in Middle Income Group based on the economic scenario of the state. The Street Width (S.W) data also couldn't be provided by the AMC so based on the survey of the expert views in AMC the average Street Width was assumed as 3.0 meter. Another reason behind assuming the Street Width as 3.0 metre is that the vehicles used to collect the $4.5 \mathrm{~m}^{3}$ and $1.1 \mathrm{~m}^{3}$ bins can't operate through roads with width less than 3.0 metre as per AMC. The cost of each $4.5 \mathrm{~m}^{3}$ bin and $1.1 \mathrm{~m}^{3}$ bin is Rs. 65000 and Rs. 30000 respectively as per AMC information. All data related to ward-wise Available number of bins (separately $1.1 \mathrm{~m}^{3}$ and $4.5 \mathrm{~m}^{3}$ bin) has been provided by AMC. The per capita waste generation rate per person has been considered as $500 \mathrm{gms} /$ day as per Ministry of Environment and Forest (MOEF) and Central Public Health and Environmental Engineering Organisation (CPHEEO) guidelines.

\section{RESULTS AND DISCUSSION}

This section has been divided into three parts, viz., results of the AHP method to estimate the weights of importance of the parameters, results from the GMDH model to establish the suitability index and lastly the case study model of Agartala Municipality.

\subsection{Weightage computation by AHP}

Table 3 shows the rank of the criterias based of expert and literature survey. The rank of the factors with respect to each criteria are presented in Table 4. Technical considerations (T1) and Available Number of Bins (A.N.B) were observed to be the most important criteria and factor respectively. The weightages which were finally obtained using Analytical Hierarchy Process (AHP) are tabulated in Table 5.

\subsection{ANN Model of S.I}

The S.I model predicted by GMDH shell (Data Science version) software showed the correlation coefficient of the predicted model as 0.994646 which indicates that the predicted model is of good quality. The accuracy of the model is shown in Figure 4a. Figure $4 \mathrm{~b}$ shows the correlation between S.I and the seven input factors P.D, S.W, W.G.R, I.G.D, C.W.B, AN.B and MIN.D. The highest positively and negatively correlated factor to S.I is W.G.R and A.N.B respectively

The 3D- plot between A.N.B, C.W.B and S.I (Figure 5a) shows that with the decrease in value of A.N.B \& C.W.B, the $S . I$ value increases, showing the highest peak at a value of less than 0.05 for A.N.B and less than 0.1 for C.W.B. The peak is at an area with value of A.N.B less than C.W.B because the weightage of A.N.B $\left(W_{\text {A.N.B }}=0.24012\right)$ is greater than weightage of W.G.R $\left(W_{\text {C.W.B }}=0.18043\right)$, so the control of A.N.B on the model is greater than C.W.B. Since C.W.B and A.N.B are non-beneficiary criterias the $S$.I is constricted to one corner. Both ANB and CWB has a very dominant effect on S.I model indicating that both availability and cost decided the suitability of a location for bin allocation followed by other attributes i.e. W.G.R, MIN.D, I.G.D, P.D and S.W.

The 3D- plot between A.N.B, W.G.R and S.I (Figure 5b) shows that with the constant value of A.N.B \& increase in value of W.G.R, the S.I value increases, showing the highest peak at a value of less than 0.05 for A.N.B and greater than or equal to 0.5 for W.G.R. This behaviour of the graph is because of the reason that A.N.B is a non-beneficiary criteria and W.G.R is a beneficiary criteria due to which decrease in value of A.N.B increase the S.I and increase in value of W.G.R increases the S.I. This indicates that the area with higher waste generation rate and lower available number of bins will have higher S.I values.

The 3D- plot between A.N.B, MIN.D and S.I (Figure 5c) shows that at higher values the MIN.D $\left(W_{\text {MIN.D }}=0.0968\right)$ the S.I value spikes up at a lower value of A.N.B. This indicates that if the minimum distance between collection bins in an area is more the suitability of that area for bin allocation increases. It was also observed that at extremely lower value of both MIN.D and A.N.B, the S.I value substantially increa-
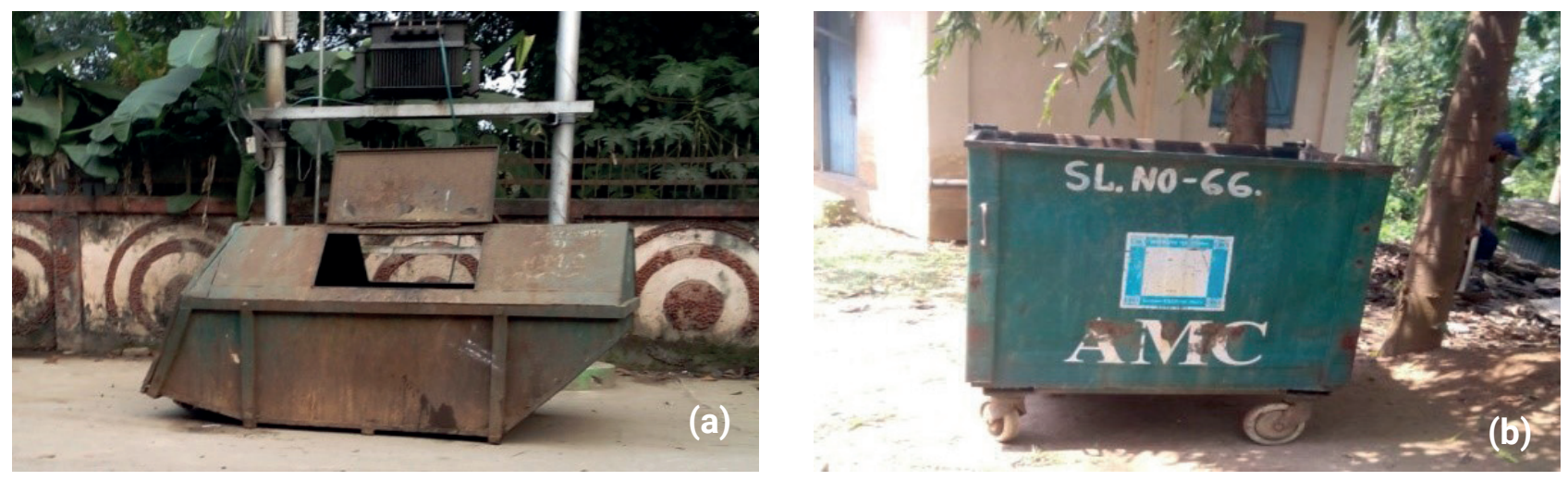

FIGURE 3: Pictures of 2-Types of containers used by AMC for secondary collection. (a) 4.5 cu. Meter Bin - (b) 1.1 cu. Meter Bin. 
TABLE 2: Data of AMC for computing S.I from the model.

\begin{tabular}{|c|c|c|c|c|c|c|c|c|}
\hline Ward no. & Name & P.D. & S.W. & W.G.R & I.G.D & C.W.B. & A.N.B & MIN.D \\
\hline 1 & Barjala & 2621.25 & 3.00 & 71.00 & 2 & 1416818 & 8.80 & 277 \\
\hline 2 & Lichubagan & 4341.56 & 3.00 & 61.79 & 2 & 1338791 & 22.30 & 738 \\
\hline 3 & Kunjaban & 6932.91 & 3.00 & 44.95 & 2 & 879600 & 34.40 & 403 \\
\hline 4 & Chanmari & 3413.73 & 3.00 & 66.41 & 2 & 1291582 & 13.20 & 383 \\
\hline 5 & Indranagar & 5330.69 & 3.00 & 72.38 & 2 & 1512264 & 6.70 & 500 \\
\hline 6 & Nandan nagar & 4203.40 & 3.00 & 65.13 & 2 & 1256836 & 14.30 & 199 \\
\hline 7 & Abhoynagar & 17261.41 & 3.00 & 57.47 & 2 & 1163327 & 25.50 & 192 \\
\hline 8 & Radhanagar & 15304.40 & 3.00 & 73.66 & 2 & 1489336 & 6.60 & 576 \\
\hline 9 & Ranjit nagar & 8203.06 & 3.00 & 64.14 & 2 & 1345291 & 15.60 & 303 \\
\hline 10 & Raj nagar & 7347.33 & 3.00 & 80.76 & 2 & 1682973 & 2.20 & 1434 \\
\hline 11 & West joynagar & 21851.74 & 3.00 & 47.86 & 2 & 1074527 & 33.50 & 250 \\
\hline 12 & Ramnagar & 20162.76 & 3.00 & 59.95 & 2 & 1173182 & 21.00 & 251 \\
\hline 13 & West krishnanagar & 20065.60 & 3.00 & 49.20 & 2 & 879918 & 30.90 & 288 \\
\hline 14 & Krishnanagar & 29679.67 & 3.00 & 35.28 & 2 & 673709 & 45.50 & 270 \\
\hline 15 & Dimsagar/ banamalipur & 17250.91 & 3.00 & 40.54 & 2 & 788273 & 39.95 & 333 \\
\hline 16 & Dhaleshwar & 11596.49 & 3.00 & 60.53 & 2 & 1189000 & 17.70 & 329 \\
\hline 17 & Khayerpur & 3805.25 & 3.00 & 57.28 & 2 & 1100473 & 22.10 & 300 \\
\hline 18 & Shibnagar & 9858.45 & 3.00 & 42.62 & 2 & 815918 & 36.60 & 260 \\
\hline 19 & West shibnagar & 16920.22 & 3.00 & 59.78 & 2 & 1197491 & 18.85 & 210 \\
\hline 20 & Town pratapgar & 18757.87 & 3.00 & 39.04 & 2 & 718473 & 41.00 & 325 \\
\hline 21 & Shantipara & 11729.63 & 3.00 & 0.00 & 2 & 0 & 79.00 & 241 \\
\hline 22 & Melarmath & 12704.85 & 3.00 & 34.77 & 2 & 544127 & 43.10 & 214 \\
\hline 23 & Bardowali & 11992.06 & 3.00 & 74.02 & 2 & 1499182 & 4.40 & 1000 \\
\hline 24 & Bhotto pukur & 9310.80 & 3.00 & 66.29 & 2 & 1403900 & 13.40 & 550 \\
\hline 25 & Arundhuti nagar & 13741.97 & 3.00 & 53.81 & 2 & 1121318 & 24.50 & 623 \\
\hline 26 & South badharghat & 4152.72 & 3.00 & 77.14 & 2 & 1584327 & 1.10 & 1434 \\
\hline 27 & Sidhi ashram & 5080.59 & 3.00 & 45.53 & 2 & 779964 & 35.30 & 365 \\
\hline 28 & Rajlakhie nagar & 5265.18 & 3.00 & 45.79 & 2 & 729245 & 31.90 & 214 \\
\hline 29 & Arundhuti nagar & 11538.46 & 3.00 & 77.33 & 2 & 1589509 & 2.20 & 1434 \\
\hline 30 & Pratapgar/ west pratapgar & 9616.30 & 3.00 & 67.01 & 2 & 1423564 & 12.30 & 350 \\
\hline 31 & East pratapgar & 9616.69 & 3.00 & 79.35 & 2 & 1644627 & 0.00 & 1434 \\
\hline 32 & Jogendranagar & 8863.54 & 3.00 & 71.49 & 2 & 1430264 & 7.70 & 333 \\
\hline 33 & North jogendranagar & 9739.36 & 3.00 & 68.64 & 2 & 1410236 & 8.90 & 300 \\
\hline 34 & Aralia & 4693.64 & 3.00 & 63.06 & 2 & 1200273 & 18.70 & 400 \\
\hline 35 & East jogendranagar & 6450.13 & 3.00 & 78.55 & 2 & 1622864 & 0.00 & 1434 \\
\hline
\end{tabular}

ses which means that if both the available number of bins and minimum distance between collection bins in an area is less than the collection bins need relocation and hence the $S . I$ value of the area increases.

The 3D- plot between A.N.B, I.G.D ( $\left.\mathrm{W}_{\mathrm{I.G.D}}=0.087\right)$ and S.I (Figure $5 \mathrm{~d}$ ) depicts that areas with more of high income group have highest values of S.I but the weightage of this lower have low impact on the S.I model. The 3D- plot between A.N.B, P.D $\left(W_{P . D}=0.083\right)$ and S.I (Figure 5e) shows that the S.I. values slowly increases with a increase in value of P.D. i.e. the suitability of an area for collection bin allocation increases with increase in value of population density but increases at very slow rate indicating that P.D. has a very minimal influence on the S.I. model. The 3D- plot between A.N.B, S.W. ( $\left.W_{\text {s.W }}=0.051\right)$ and S.I (Figure 5f) represents that the value of S.I for an area increases with the decrease in street width. This might be due to the fact that S.W has the

TABLE 3: Rank of the criterias based literature survey and expert survey.

\begin{tabular}{l|c:c} 
Criteria & Abbreviation & Score \\
\hline Demographic Consideration & D1 & 2 \\
\hline Social Consideration & S1 & 3 \\
\hline Economic Consideration & E1 & 4 \\
\hline Technical Consideration & T1 & 1 \\
\hline
\end{tabular}


TABLE 4: Rank of the factors based literature survey and expert survey

\begin{tabular}{l|c|c|c|c} 
& D1 & S1 & E1 & T1 \\
\hline P.D & 1 & 3 & 5 & 6 \\
\hline S.W & 4 & 6 & 7 & 5 \\
\hline W.G.R & 2 & 1 & 4 & 4 \\
\hline I.G.D & 3 & 2 & 3 & 7 \\
\hdashline C.W.B & 4 & 3 & 1 & 2 \\
\hline A.N.B & 7 & 3 & 2 & 1 \\
\hline MIN.D & 6 & 7 & 6 & 3 \\
\hline
\end{tabular}

lowest weightage and hence least or negligible impact on the model especially in comparison to A.N.B, which has the highest impact on the model. Therefore might be due to this reason the S.I shows increased value with decrease in S.W.

\subsection{Suitability Index for the case study}

The S.I model obtained above was then applied to AMC area for finding out the ward-wise Suitability Index. The mo-
TABLE 5: Weightage computation by AHP.

\begin{tabular}{l|c:c} 
Factors & Abbreviation & AHP Weightage \\
\hline Population Density & P.D & 0.14980 \\
\hdashline Street Width & S.W & 0.07578 \\
\hline Waste Generation Rate & W.G.R & 0.15991 \\
\hline Income Group Density & I.G.D & 0.10047 \\
\hline Cost of Waste Bin & C.W.B & 0.18043 \\
\hline Available Number of Bin & A.N.B & 0.24012 \\
\hline Minimum Distance between bins & MIN.D & 0.09349 \\
\hline
\end{tabular}

del predicted the Suitability Index (S.I) value for all the 35 wards (Figure 6).

According to the S.I Model the first five wards with highest values of S.I are Ward No. 29, 31, 23, 10 and 35 with S.I values of $2.234060498,2.083174661,2.028085959$, 1.91108766 and 1.859772522 respectively.

The suitability index value for each and every location inside the Agartala Municipality Area can be obtained from

\begin{tabular}{|l|l|l|}
\hline Postprocessed results & Model fit & Predictions \\
\hline Number of observations & 800 & 200 \\
\hline Max. negative error & -1.39189 & -2.26909 \\
\hline Max. positive error & 1.0747 & 1.25886 \\
\hline Mean absolute error (MAE) & 0.109201 & 0.144452 \\
\hline Root mean square error (RMSE) & 0.178652 & 0.282605 \\
\hline Residual sum & $-2.30782 \mathrm{E}-12$ & -1.33941 \\
\hline Standard deviation of residuals & 0.178652 & 0.282525 \\
\hline Coefficient of determination $\left(\mathrm{R}^{2}\right)$ & 0.998214 & 0.989293 \\
\hline Correlation & 0.999107 & 0.994646 \\
\hline
\end{tabular}

(a)

\begin{tabular}{|l|l|l|}
\hline Name & Corr. Bars \\
\hline Suitability index & 1.000 \\
\hline A.N.B & -0.310 & \\
\hline C.W.B. & -0.250 \\
\hline W.G.R & 0.110 \\
\hline MIN.D & 0.098 \\
\hline I.G.D & 0.087 \\
\hline P.D. & 0.083 \\
\hline S.W. & 0.051 \\
\hline
\end{tabular}

(b)

\begin{tabular}{|c|c|c|c|c|c|c|c|c|}
\hline Variable & P.D. & S.W. & W.G.R & I.G.D & C.W.B. & A.N.B & MIN.D & Suitability index \\
\hline Numeric values & 1000 & 1000 & 1000 & 1000 & 1000 & 1000 & 1000 & 1000 \\
\hline Text values & 0 & 0 & 0 & 0 & 0 & 0 & 0 & 0 \\
\hline Missing values & 0 & 0 & 0 & 0 & 0 & 0 & 0 & 0 \\
\hline Unique values & 1000 & 1000 & 1000 & 1000 & 1000 & 1000 & 1000 & 1000 \\
\hline Zero values & 0 & 0 & 0 & 0 & 0 & 0 & 0 & 0 \\
\hline \multicolumn{9}{|l|}{ Most frequent } \\
\hline Min. value & 0.000208657 & 0.00352632 & 0.000976689 & 0.000370506 & 0.00442318 & 0.000199995 & 0.00015408 & 0.296348 \\
\hline Max. value & 0.997402 & 0.999579 & 0.999919 & 0.999481 & 0.999749 & 0.999224 & 0.999228 & 102.936 \\
\hline Median & 0.497878 & 0.508169 & 0.508874 & 0.514606 & 0.482223 & 0.500705 & 0.515461 & 1.39735 \\
\hline Mean value & 0.496112 & 0.504421 & 0.505048 & 0.509758 & 0.482955 & 0.493987 & 0.500926 & 2.08774 \\
\hline Std. deviation & 0.287683 & 0.291957 & 0.288516 & 0.297021 & 0.282179 & 0.293303 & 0.288156 & 3.97525 \\
\hline $2 \sigma$ outliers & 0 & 0 & 0 & 0 & 0 & 0 & 0 & 14 \\
\hline $3 \sigma$ outliers & 0 & 0 & 0 & 0 & 0 & 0 & 0 & 7 \\
\hline $4 \sigma$ outliers & 0 & 0 & 0 & 0 & 0 & 0 & 0 & 4 \\
\hline
\end{tabular}

(c)

FIGURE 4: (a) Accuracy of the Global model Predicted by GMDH Shell; (b) Correlation of the 7-factors with Sutability Index (S.I); (c) Statistics of the Global model Predicted by GMDH Shell. 
(a)

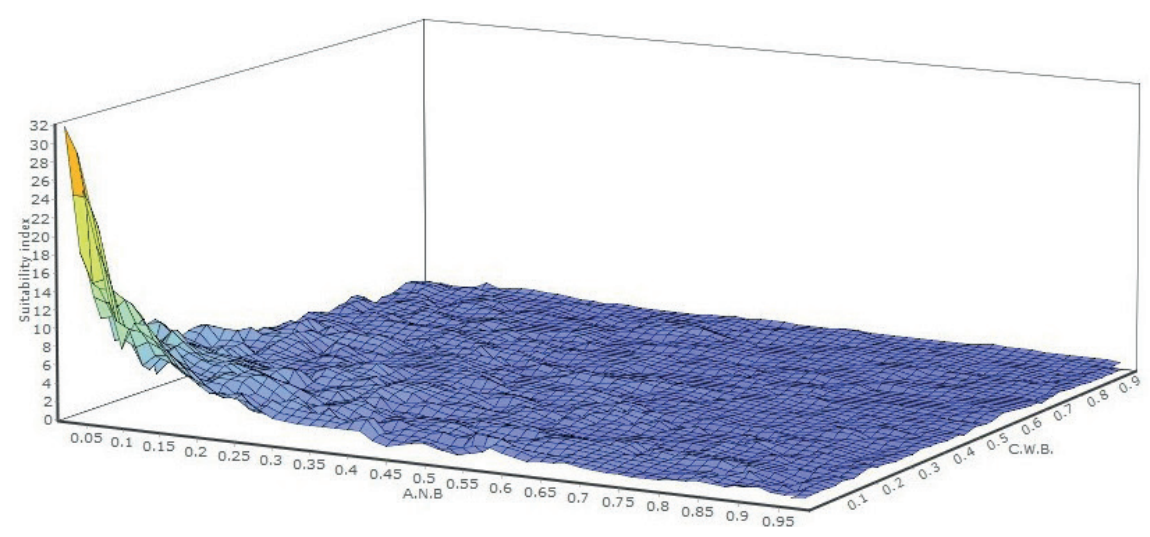

(b)

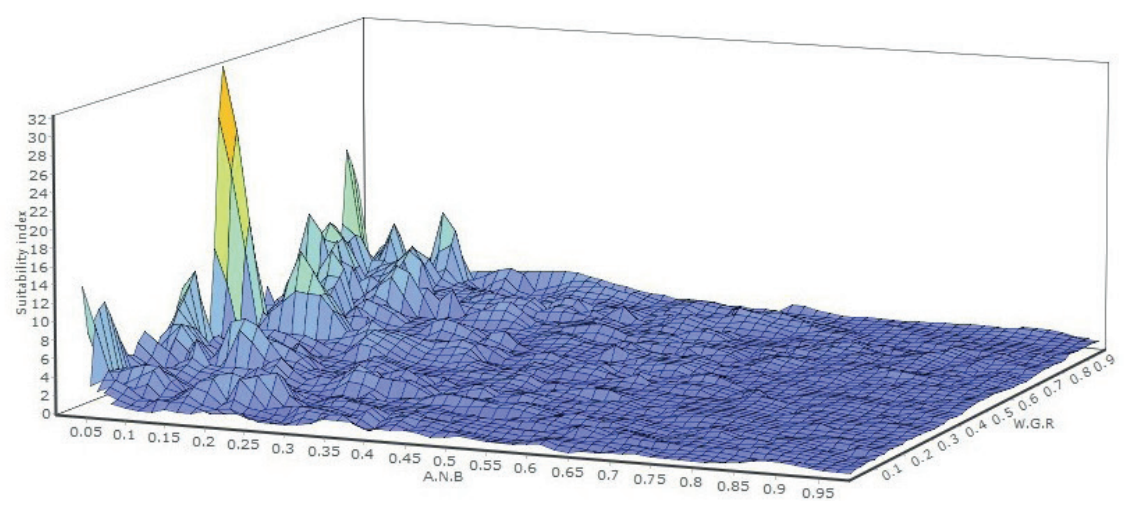

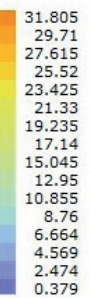

(c)

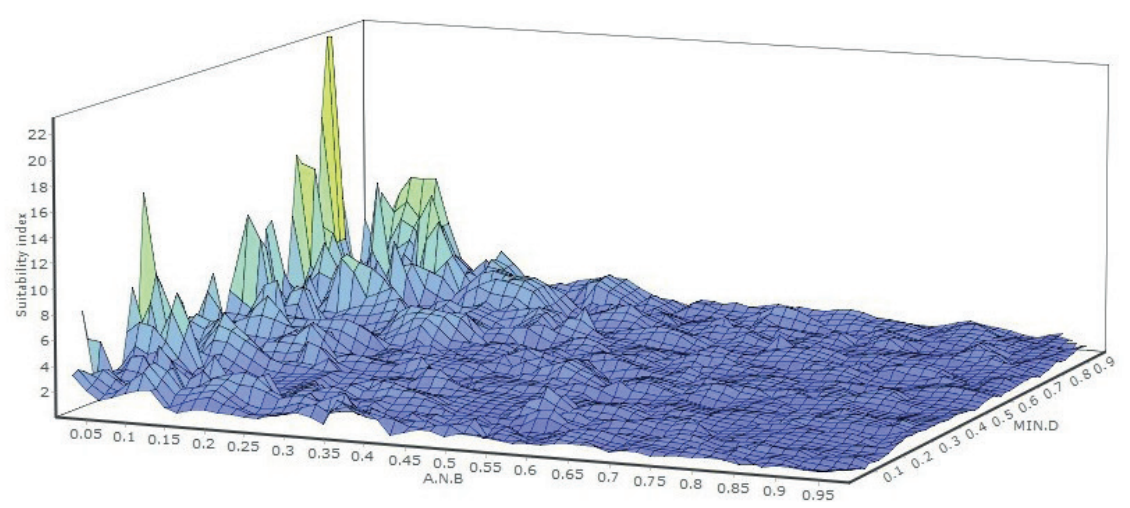

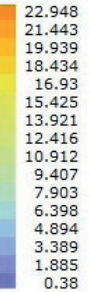

(d)

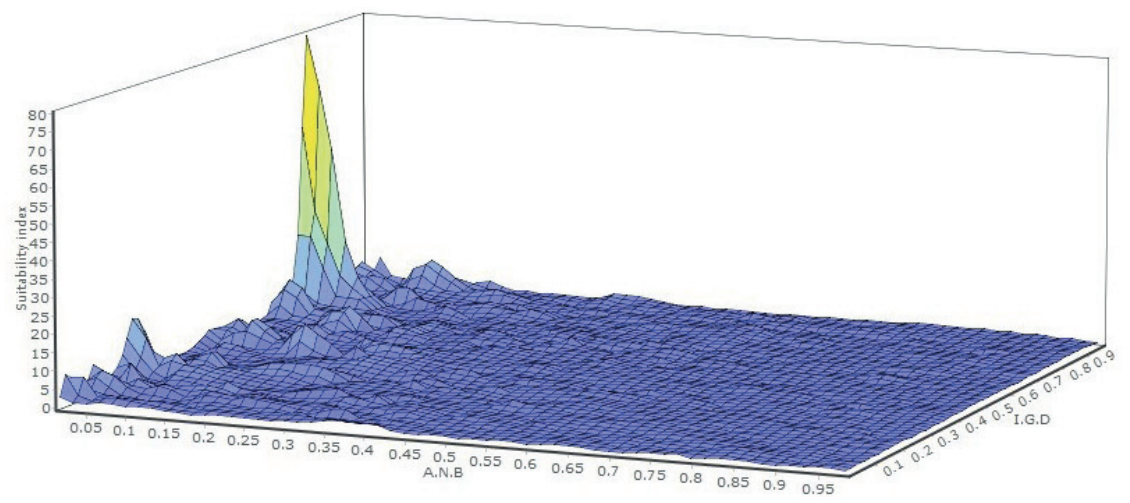

79.449
74.479
68.909
63.9099
58.639
53.369
43.099
42.829
42.559
37.289
32.219
26.749
21.479
21.499
16.209
10.939
5.659
0.3999
0.399

FIGURE 5a-d: (a) 3D-Plot between A.N.B, C.W.B and S.I; (b) 3D-Plot between A.N.B, W.G.R and S.I; (c) 3D-Plot between A.N.B, MIN.D and S.I; (d) 3D-Plot between A.N.B, I.G.D and S.I. 
(e)

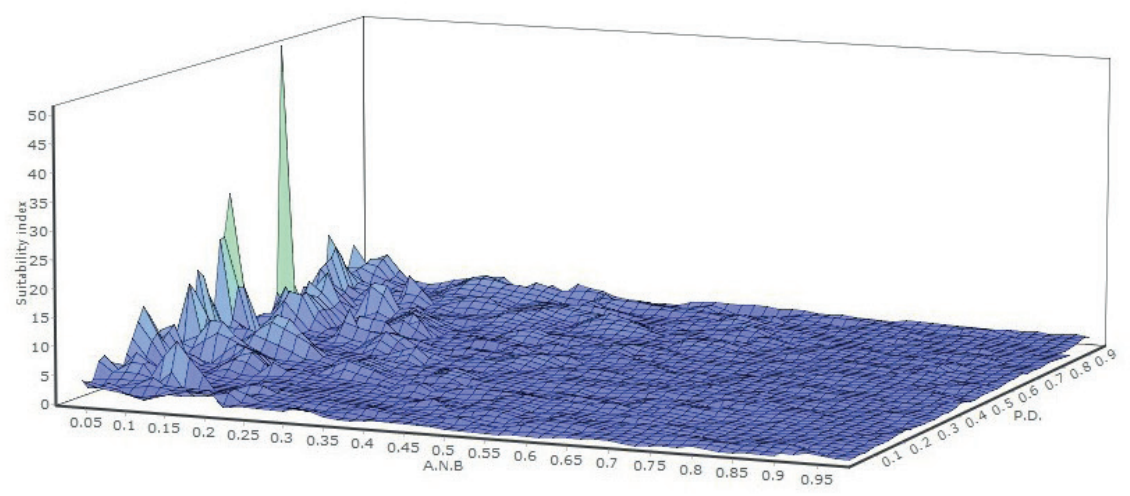

(f)

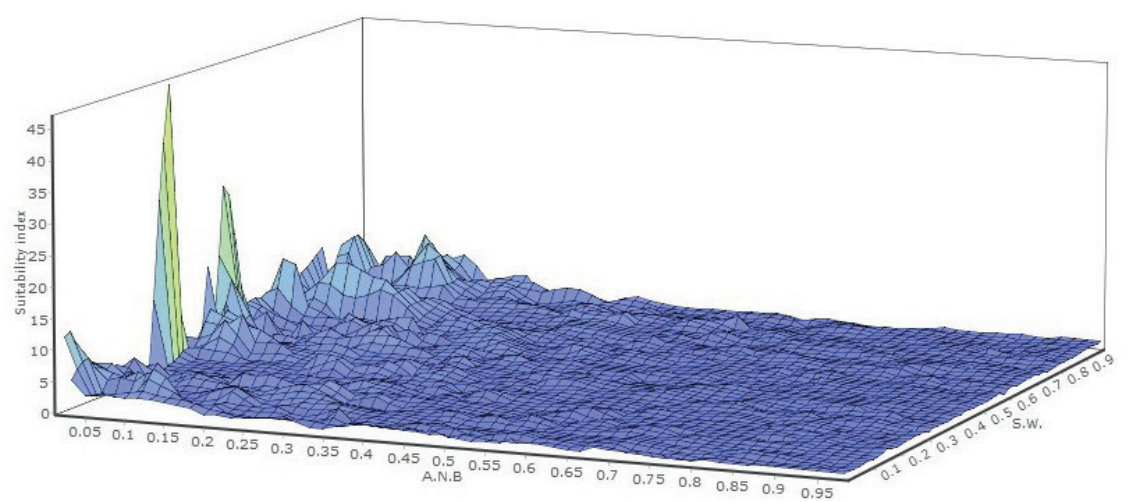

FIGURE 5e-f: (e) 3D-Plot between A.N.B, P.D and S.I; (f) 3D-Plot between A.N.B, S.W and S.I.

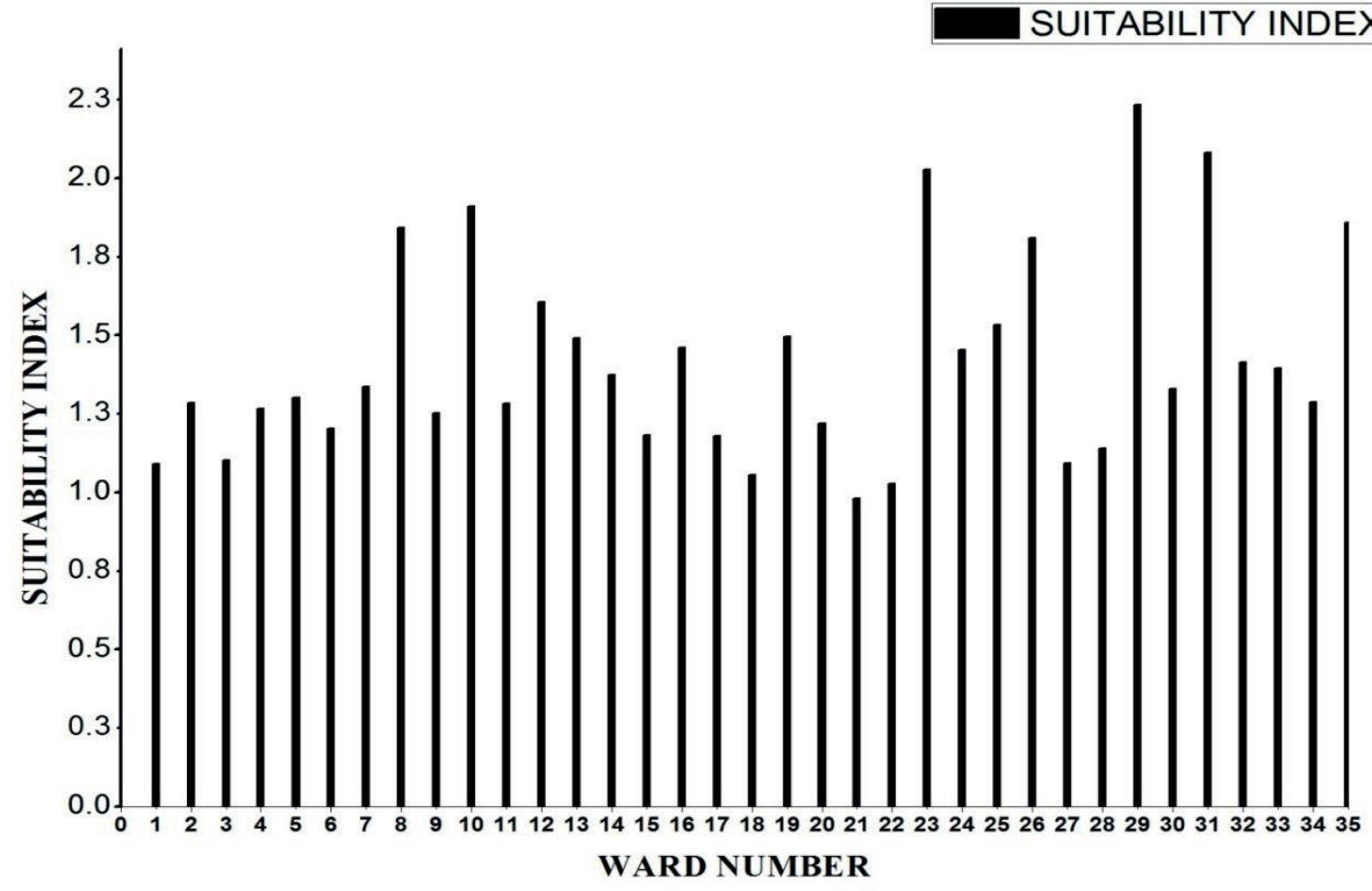

FIGURE 6: Ward-wise Suitability Index.

the contour map shown in Figure 7, which has been made using Surfer 12. Using this map, the areas in most urgent need of collection bins can be found out and the same can be provided with collection bins at the earliest. Subsequently the areas with low S.I values can be provided with collection bin facilities at the earliest convenience. 


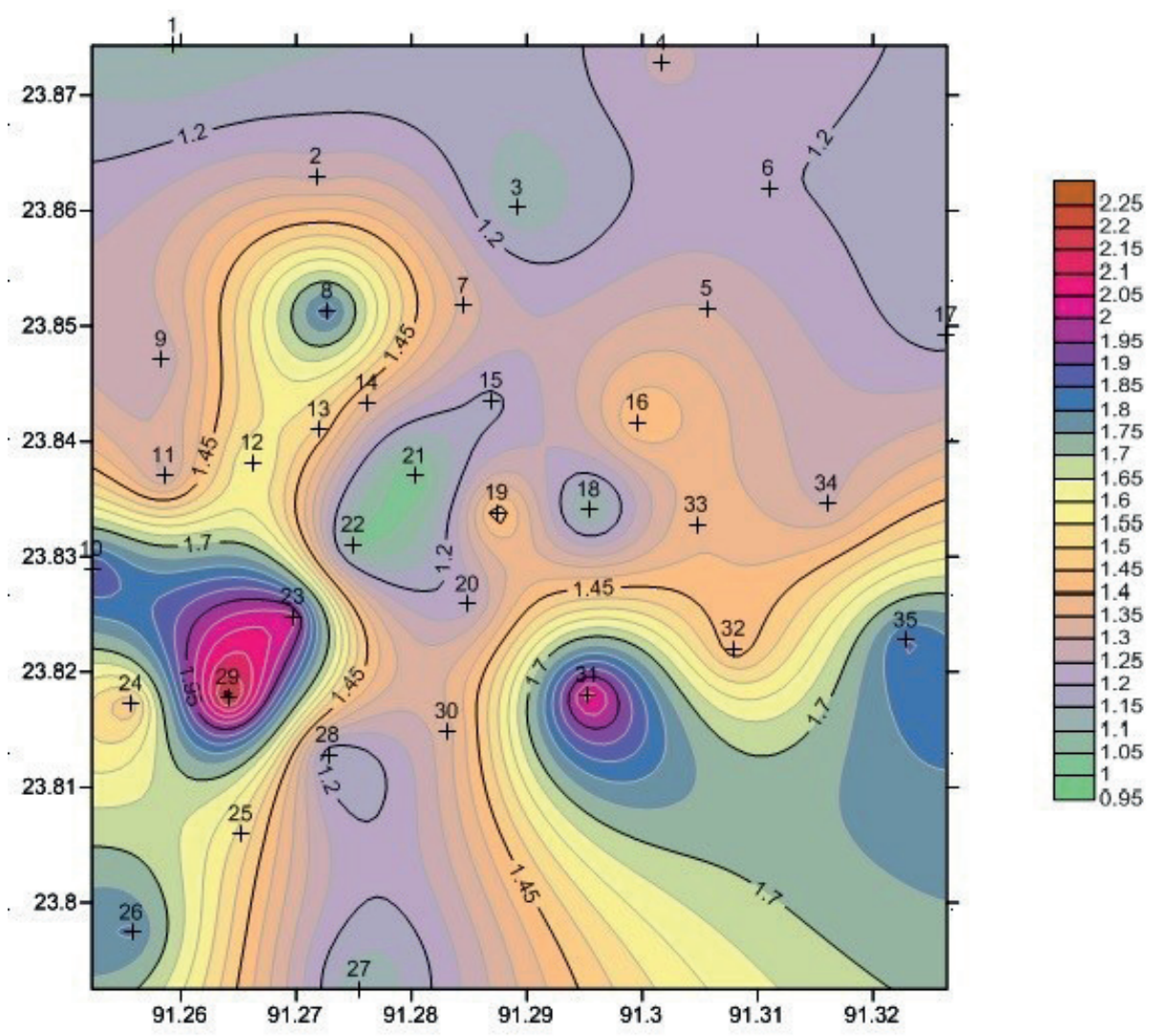

FIGURE 7: Contour Map of Suitability Index (X-axis: Longitude, Y-axis: Latitude).

\section{CONCLUSIONS}

From the study conducted in this research it is quite clear that the existing location of collection bins are uneven with many wards provided with absolutely no bin. Also it has been observed that there is absolutely no relation between numbers of bins in a ward and its population density. These problems are due to manual placement of bins with absolutely no use of any optimization technique. An optimization technique will help distribute the bins evenly along the wards at point where waste generation is occurring.

This work focuses on formulation and implementation of an innovative Suitability Index by using Analytical Hierarchy Process (AHP) and Artificial Neural Network (ANN). The S.I was found to depend on seven factors which were grouped under beneficiary and non-beneficiary factors. Population Density (P.D), Street Width (S.W), Waste Generation Rate (W.G.R), Income Group Distribution (I.G.D) and Average Minimum Distance between the bins (MIN D.) are beneficiary factors and Available Number of Bins (A.N.B) and Cost of Waste Bins (C.W.B) are non-beneficiary factors. The factor Available Number of Bins (A.N.B) was found to have the highest impact on the model followed by C.W.B, W.G.R, MIN D., I.G.D, P.D and S.W.

The case study conducted in Agartala Municipal area using this model showed that Ward No. 29, 31, 23, 10 and 35 are the first five wards with high Suitability Index value. These wards should be provided with collection bin facilities at the earliest. Using the contour map (Figure 7), the S.I. value at each and every location inside the Agartala Municipality can be obtained with known latitude and longitude.

This index will particularly help the developing countries with resource constraint and unskilled labor involvement in Solid Waste Management to easily locate areas/ wards/districts needing most urgently collection bins with an easily available set of data and help increase the collection efficiency. The data related to the seven factors incorporated in this model for computation of Suitability Index are generally easily available with all Government bodies and hence the practical applicability of this Suitability Index is very high, easy and convenient.

\section{REFERENCES}

Arribas, C. A., Blazquez, C. A., \& Lamas, A. (2010). Urban solid waste collection system using mathematical modelling and tools of geographic information systems. Waste Management and Research, 28(4), 355-363. https://doi.org/10.1177/0734242X09353435

Beaumont, J. R. (1987). Location-allocation models and central place theory. (G. Ghosh, A., \& Rushton, Ed.), Spatial analysis and location-allocation models. Van Nostrand Reinhold Company.

Coutinho-Rodrigues, J., Tralhão, L., \& Alçada-Almeida, L. (2012). A bi-objective modeling approach applied to an urban semi-desirable facility location problem. European Journal of Operational Research, 223(1), 203-213. https://doi.org/10.1016/j.ejor.2012.05.037

Di Felice, P. (2014). Integration of Spatial and Descriptive Information to Solve the Urban Waste Accumulation Problem: A Pilot Study. Procedia - Social and Behavioral Sciences, 147, 592-597. https:// doi.org/10.1016/j.sbspro.2014.07.636

El-Hallaq, M. A., \& Mosabeh, R. (2019). Optimization of Municipal Solid Waste Management of Bins Using GIS. A Case Study: Nuseirat City. Journal of Geographic Information System, 11(01), 32-43. https://doi.org/10.4236/jgis.2019.111003 
Erfani, S. M. H., Danesh, S., Karrabi, S. M., \& Shad, R. (2017). A novel approach to find and optimize bin locations and collection routes using a geographic information system. Waste Management and Research, 35(7), 776-785. https://doi. org/10.1177/0734242X17706753

Erfani, S. M. H., Danesh, S., Karrabi, S. M., Shad, R., \& Nemati, S. (2018). Using applied operations research and geographical information systems to evaluate effective factors in storage service of municipal solid waste management systems. Waste Management, 79, 346-355. https://doi.org/10.1016/j.wasman.2018.08.003

Farlow, S. J. (1981). The gmdh algorithm of ivakhnenko. American Statistician, 35(4), 210-215. https://doi.org/10.1080/00031305.1981. 10479358

Ghiani, G., Laganà, D., Manni, E., \& Triki, C. (2012). Capacitated location of collection sites in an urban waste management system. Waste Management, 32(7), 1291-1296. https://doi.org/10.1016/j. wasman.2012.02.009

Ghiani, G., Manni, A., Manni, E., \& Toraldo, M. (2014). The impact of an efficient collection sites location on the zoning phase in municipal solid waste management. Waste Management, 34(11), 19491956. https://doi.org/10.1016/j.wasman.2014.05.026

Ghose, M. K., Dikshit, A. K., \& Sharma, S. K. (2006). A GIS based transportation model for solid waste disposal - A case study on Asansol municipality. Waste Management, 26(11), 1287-1293. https://doi. org/10.1016/j.wasman.2005.09.022

Ghosh, S., Chakraborty, T., Saha, S., Majumder, M., \& Pal, M. (2016). Development of the location suitability index for wave energy production by ANN and MCDM techniques. Renewable and Sustainable Energy Reviews, 59, 1017-1028. https://doi.org/10.1016/j. rser.2015.12.275

González-Torre, P. L., Adenso-Díaz, B., \& Ruiz-Torres, A. (2003). Some comparative factors regarding recycling collection systems in regions of the USA and Europe. Journal of Environmental Management, 69(2), 129-138. https://doi.org/10.1016/S03014797(03)00109-9

Hemmelmayr, V. C., Doerner, K. F., Hartl, R. F., \& Vigo, D. (2013). Models and Algorithms for the Integrated Planning of Bin Allocation and Vehicle Routing in Solid Waste Management. Transportation Science, 48(1), 103-120. https://doi.org/10.1287/trsc.2013.0459

Kao, J. J., \& Lin, T. I. (2002). Shortest service location model for planning waste pickup locations. Journal of the Air and Waste Management Association, 52(5), 585-592. https://doi.org/10.1080/10473 289.2002.10470807

Karadimas, N. V., \& Loumos, V. G. (2008). GIS-based modelling for the estimation of municipal solid waste generation and collection Waste Management and Research, 26(4), 337-346. https://doi. org/10.1177/0734242X07081484
Khan, D., \& Samadder, S. R. (2016). Allocation of solid waste collection bins and route optimisation using geographical information system: A case study of Dhanbad City, India. Waste Management and Research, 34(7), 666-676. https://doi. org/10.1177/0734242X16649679

Mondal, M. M., Speier, C. J., \& Weichgrebe, D. (2019). Multi-stage optimization approach for sustainable municipal solid waste collection systems in urban areas of Asia's newly industrialized countries. Environmental Management, 63(4), 536-553. https://doi. org/10.1007/s00267-018-1130-6

National Solid Waste Association of India (NSWAI). (2008). Urban Municipal Waste Management Newsletter. ENVIS, pp. 1-8.

Nithya, R., Velumani, A., \& Senthil Kumar, S. R. R. (2012). Optimal location and proximity distance of municipal solid waste collection bin using GIS: A case study of Coimbatore city. WSEAS Transactions on Environment and Development, 8(4), 107-119.

Parrot, L., Sotamenou, J., \& Dia, B. K. (2009). Municipal solid waste management in Africa: Strategies and livelihoods in Yaoundé Cameroon. Waste Management, 29(2), 986-995. https://doi. org/10.1016/j.wasman.2008.05.005

Purkayastha, D., Majumder, M., \& Chakrabarti, S. (2015). Collection and recycle bin location-allocation problem in solid waste management : A review. Pollution, 1(2), 175-191.

Rathore, P., Sarmah, S. P., \& Singh, A. (2019). Location-allocation of bins in urban solid waste management: a case study of Bilaspur city, India. Environment, Development and Sustainability, (0123456789). https://doi.org/10.1007/s10668-019-00347-y

Tralhão, L., Coutinho-Rodrigues, J., \& Alçada-Almeida, L. (2010). A multiobjective modeling approach to locate multi-compartment containers for urban-sorted waste. Waste Management, 30(12) 2418-2429. https://doi.org/10.1016/j.wasman.2010.06.017

Valeo, C., Baetz, B. W., \& Tsanis, I. K. (2002). Location of Recycling Depots with GIS. Journal of Urban Planning and Development, 124(2), 93-99. https://doi.org/10.1061/(asce)0733-9488(1998)124:2(93)

Vijay, R., Gupta, A., Kalamdhad, A. S., \& Devotta, S. (2005). Estimation and allocation of solid waste to bin through geographical information systems. Waste Management and Research, 23(5), 479-484. https://doi.org/10.1177/0734242X05057763

Vu, H. L., Ng, K. T. W., \& Bolingbroke, D. (2018). Parameter interrelationships in a dual phase GIS-based municipal solid waste collection model. Waste Management, 78, 258-270. https://doi. org/10.1016/j.wasman.2018.05.050

Zia, H., \& Devadas, V. (2008). Urban solid waste management in Kanpur: Opportunities and perspectives. Habitat International, 32(1), 58-73. https://doi.org/10.1016/j.habitatint.2007.08.001 